\title{
Optimization of surface reflectance for silicon solar cells
}

\author{
Gagik Ayvazyan $^{1 *}$, Razmik Barseghyan ${ }^{1}$, and Sergey Minasyan ${ }^{1}$ \\ ${ }^{1}$ National Polytechnic University of Armenia, Teryan str. 105, Yerevan, Armenia
}

\begin{abstract}
A study on the formation of black silicon (b-Si) antireflection layers on crystalline Si wafers using $\mathrm{SF}_{6} / \mathrm{O}_{2}$ gas mixture in a reactive ion etching method is presented. The process is low-temperature, fast and does not depend on the crystallographic orientation of the Si wafer. The b-Si layers have demonstrated average reflectance values of $4 \%$ and $5 \%$ for mono- and polycrystalline $\mathrm{Si}$ wafers respectively, feature that is suitable for the fabrication of high efficiency solar cells. Passivation of b-Si antireflection layers by suitable different thin films can significantly reduce needle-like surface recombination losses.
\end{abstract}

\section{Introduction}

Silicon ( $\mathrm{Si}$ ) with various structural morphologies is widely used for solar cells and other electro-optical devices. However, flat Si surfaces have a high natural reflectivity with a strong spectral dependence. The minimization of reflection losses is of crucial importance for high efficiency Si solar cells, and hence, a variety of approaches has been developed to this end, in many cases specific to a particular surface morphology [1].

Efficient suppression of reflection in a broad spectral range has been achieved by deep surface texturing. Photolithography-free wet chemical texturing processes have been used in order to produce pyramid-like structures in the Si surface [2-4]. Chemical solutions based on potassium hydroxide $(\mathrm{KOH})$, sodium hydroxide $(\mathrm{NaOH})$ and tetramethylammonium hydroxide $\left(\left(\mathrm{CH}_{3}\right)_{4} \mathrm{NOH}\right)$ have been employed. However, despite the low reflectance values chemical texturing processes have several drawbacks. For large volume production of solar cells, high amounts of deionized water (DI) and chemicals represent an environmental and financial issue. Also, the large penetration of the etched pyramids into the $\mathrm{Si}$ wafer complicates solar cell design. In addition, the reflectivity of these surfaces increases rapidly with the angle of light incidence. Chemical processes cannot be performed just in one wafer face (front surface) as is required, since texturing in the back surface reduces the quality of the dielectric rear surface passivation.

Recently dry etching, in particular, reactive ion etching (RIE), has attracted much attention in order to produce highly textured surfaces. Structures obtained by RIE are typically referred to as "black silicon" (b-Si) or "silicon nanoforest", which is a needle-like surface nanostructure where needles are made of single-crystal Si $[5,6]$.

The b-Si formation RIE method exhibits some distinct advantages. First, it is a reliable and reproducible, yet self-organized process that does not necessitate any additionally applied mask. Second, the method leaves crystallographic intact nanostructure surfaces free of chemical contaminations, in contrast, e.g., to structures obtained by wet etching. Third, it cannot only be applied to poly- and monocrystalline wafers, but also to amorphous or crystalline $\mathrm{Si}$ thin films.

The unusual photoelectric characteristics, combined with the semiconducting properties of silicon make b-Si interesting for solar cells applications as antireflection layers [7-9]. In particular, these nanostructures as antireflection layer increase the surface area of the solar cells, and increase the amount of sunlight that is captured rather than reflected back from the cells (Fig.1). Modifying the material in this way makes it a lot less reflective, allowing solar cells that use it to trap light even when it's coming from very low angles.

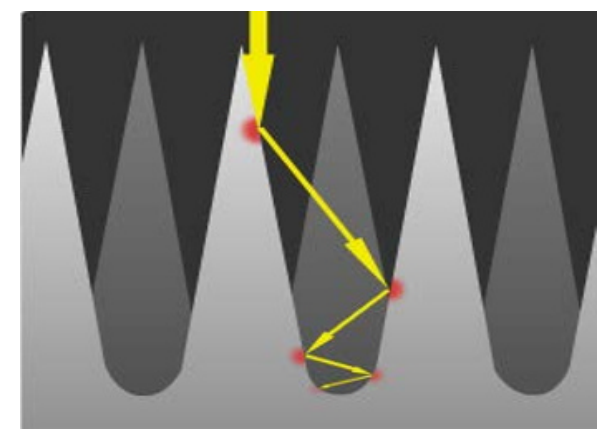

Fig. 1. Schematic depicting of b-Si

Our research is focused on developing high efficiency $\mathrm{Si}$ solar cells by using b-Si antireflection layers.

\section{Solar cells fabrication}

Corresponding author: agagarm@gmail.com 
Construction of b-Si solar cell is shown in Fig. 2, which includes metal back contact 1, p-n junction 2, metal front contact 3 and b-Si layer 4.

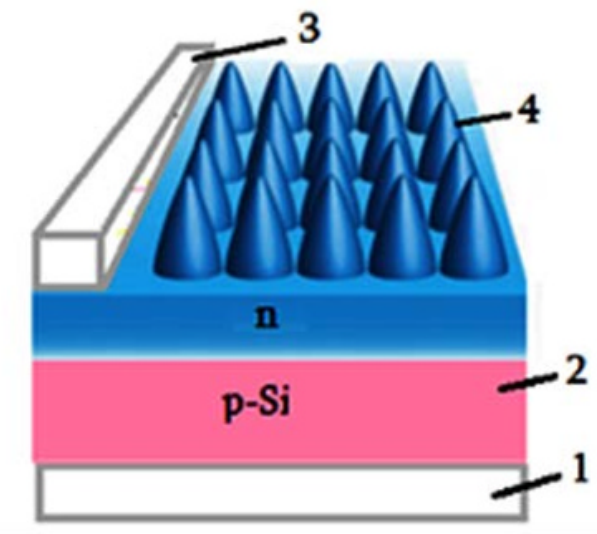

Fig. 2. Construction of b-Si solar cell

Our previous studies have shown that during the solar cell processing steps such as diffusion and oxidation, the height of the b-Si layer is reduced [10]. In the light of the above-mentioned, a production process of b-Si solar cells was developed, according to which, the b-Si with preferable height of needles is formed after the main chemical and thermal treatment of the technological process [10].

Two kinds of source material have been used: double-side polished p-type (boron-doped) monocrystalline (mono-Si) and polycrystalline Si (poly$\mathrm{Si})$ wafers with thickness of $400 \mu \mathrm{m}$ and resistivity of 1$3 \Omega \mathrm{cm}$. Subsequently, the following process steps in the production line were performed.

1.Pre-cleaning and removal. The as-cut wafers were polished using a hydrofluoric acid (HF) and nitric acid $\left(\mathrm{HNO}_{3}\right)$ solution at room temperature for 1-2 min. The process is completed by washing in DI and drying in $\mathrm{N}_{2}$.

2.Formation of $p-n$ junction. The $p-n$ junction of all solar cells was formed by diffusion of phosphorus from a spin-on dopant through the front surfaces. The samples are spun at a speed of 2500 turns/min for $20 \mathrm{~s}$, followed by a prebaking at $200^{\circ} \mathrm{C}$ for $5 \mathrm{~min}$ and at $400^{\circ} \mathrm{C}$ for 10 min on the hot plate. The diffusion was performed in an atmosphere of $25 \% \mathrm{O}_{2}$ and $75 \% \mathrm{~N}_{2}$ in a closed quartz tube mounted in an oven at $950^{\circ} \mathrm{C}$ for $20 \mathrm{~min}$. The diffusion resulted in the formation of n-type regions (junction depth ranges from 0.9 to $0.95 \mu \mathrm{m}$ ) below the front surfaces with respective sheet resistances of 40-45 $\Omega /$ sq. This leads to the growth of a thin layer of phosphorus pentoxide $\left(\mathrm{P}_{2} \mathrm{O}_{5}\right)$ glass, which was removed from all samples by etching in concentrated HF.

3. Formation of metal back contact. The $800 \mathrm{~nm}$ thick Al layer was deposited on back surface by vacuum evaporation. The contact was annealed at $600^{\circ} \mathrm{C}$ (above the $\mathrm{Al} / \mathrm{Si}$ eutectic temperature) for $15 \mathrm{~min}$ in atmosphere of $\mathrm{N}_{2}$. The purpose of this treatment is to reduce the contact resistance and recombination by $\mathrm{Al} / \mathrm{Si}$ alloying and $\mathrm{p}^{+}$- type doping of the rear-contact region.

4. Formation of metal front contact. The $70 \mathrm{~nm}$ thick $\mathrm{Ti}$ and $200 \mu \mathrm{m}$ thick Ag layers were deposited on the front surfaces of all samples by vacuum evaporation.
Then, an array of slits $50 \mu \mathrm{m}$ wide, parallel to one side of the cell and separated by $2 \mathrm{~mm}$ pitch was opened in the $\mathrm{Ti}$ and Ag layers by photolithographic patterning and HF etching. The front contacts have not been annealed.

5. Formation of b-Si layer. The antireflection b-Si layers on the front surfaces of Si wafers was fabricated by RIE method in a gas mixture of sulfur hexafluoride $\left(\mathrm{SF}_{6}\right)$ and $\mathrm{O}_{2}$ by multi-cathode RIE equipment (homemaking). The mixture $\mathrm{SF}_{6} / \mathrm{O}_{2}$ is non-toxic and easy to handle. The process pressure was $55 \mathrm{mT}$ Torr and gas flow rates were $75 \mathrm{~cm}^{3} / \mathrm{min}$ and $40 \mathrm{~cm}^{3} / \mathrm{min}$ for $\mathrm{SF}_{6}$ and $\mathrm{O}_{2}$, respectively. Samples were placed on the water-cooled $\left(23^{\circ} \mathrm{C}\right)$ bottom electrode that was powered by a 13.56 $\mathrm{MHz}$ RF generator. The etch durations were kept constant at $10 \mathrm{~min}$.

Two solar cells on mono-Si and poly-Si wafers with conventional pyramidal surfaces were used as references: a pyramidal surface etched before formation of p-n junction by the $\mathrm{KOH}$ solution at $80^{\circ} \mathrm{C}$ for $20 \mathrm{~min}$. There are no additional antireflection and passivation coatings on either type of solar cells under study.

\section{Results and discussion}

The morphology of the b-Si was observed by scanning electron microscope (SEM). To identify needle density, SEM micrographs were acquired at $30^{\circ}$ tilt angle. Crosssectional views at $10^{\circ}$ tilt angle were used to measure needle height. Optical reflectance of the b-Si wafers was detected using a spectrophotometer T70 UV-VIS with an integrating sphere. The performance parameters of b-Si solar cells were characterized using illuminated currentvoltage under one sun global spectrum of AM1.5.

The self-formation of the $\mathrm{Si}$ needles occurs as a consequence of spatial inhomogeneities in deposition and etching processes during plasma processing caused by the specific interactions of nucleation and deposition of the passivation system and the removal by ion bombardment and chemical etching $[5,6]$. As a consequence of the interaction of different spatial inhomogeneities a high density of etching residues or the passivation layer formed during the early stages of the etching process. The local passivation acts as selfmasked areas causing the b-Si formation. In the case of $\mathrm{SF}_{6} / \mathrm{O}_{2}$ etching components, the b-Si formation is due to a competition among the etching process of silicon by fluorine radicals, the deposition of a $\mathrm{SiO}_{\mathrm{x}} \mathrm{F}_{\mathrm{y}}$ film due the presence of oxygen, and the etching of this film by reactive ions like $\mathrm{SF}_{\mathrm{x}}{ }^{*}$, fluorine $\left(\mathrm{F}^{*}\right)$ and oxygen $\left(\mathrm{O}^{*}\right)$ radicals, as well.

SEM image of b-Si consisting of random needle like whiskers fabricated on mono-Si wafer is shown in Fig. 3. 


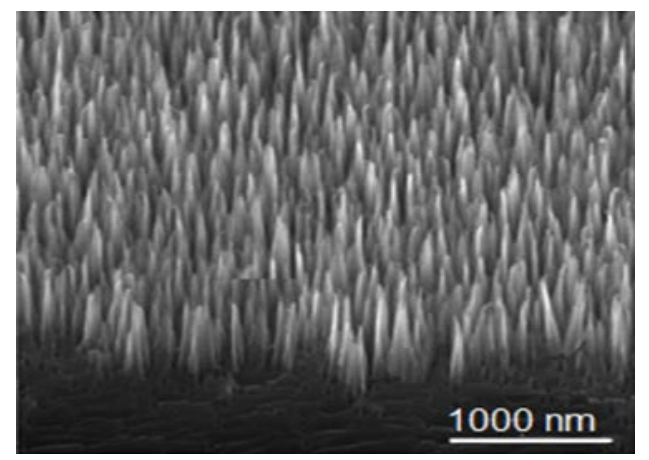

Fig. 3. SEM image of b-Si fabricated on mono-Si wafer

The surface morphology is different for two types of wafer. The needles fabricated on mono-Si are longer and have regular shapes while those on poly-Si are shorter with irregular shapes representing a rougher surface. The height of the needles ranges from about $560 \mathrm{~nm}$ to about $730 \mathrm{~nm}$ with an average height of $640 \mathrm{~nm}$ for those fabricated on mono-Si. Those formed on poly-Si are shorter and have an average height of $590 \mathrm{~nm}$. The needles are randomly distributed over the Si wafer and have a surface density of $15-17$ site/ $\mu \mathrm{m}^{2}$ and the aspect ratios (height to average width at half maximum) of greater than 20. Their diameter at the bottom of the needles ranges from 40 to $50 \mathrm{~nm}$. The tip diameter of the needles can be much smaller than $3 \mathrm{~nm}$.

Fig. 4 shows the reflectance of b-Si solar cells for mono-Si and poly-Si wafers. Very little light is reflected by the Si for wavelengths below $1000 \mathrm{~nm}$. Spectrumweighted average reflectance from 400 to $1000 \mathrm{~nm}$ wavelengths is $4 \%$ and $5 \%$ for mono-Si and poly-Si wafers, respectively. The solar cells based on the pyramidal surface, used as reference, exhibits the highest average reflectance up to $8 \%$ (not shown).

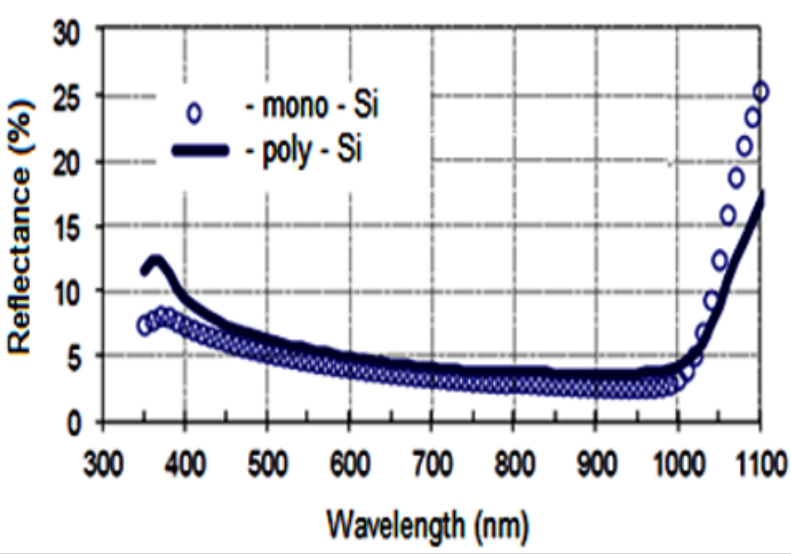

Fig. 4. Reflectance of b-Si solar cells on mono-Si and poly-Si wafers

Table I shows the performance parameters (such as open circuit voltage - $V_{o c}$, short-circuit current - $I_{s c}$, fill factor $-F F$, and conversion efficiency $-\mu$ ) of solar cells on mono-Si and poly-Si wafers including the reference solar cells (conventional pyramidal surface).

Table 1. The parameters of solar cells.

\begin{tabular}{|c|c|c|}
\hline Wafer & Solar Cell & Parameters \\
\hline
\end{tabular}

\begin{tabular}{|l|l|c|c|c|c|}
\hline \multirow{2}{*}{ Mono-Si } & Reference & $\begin{array}{c}\mathrm{V}_{\mathrm{oc}} \\
\mathrm{mV}\end{array}$ & $\begin{array}{c}\mathrm{I}_{\mathrm{sc}}, \\
\mathrm{mA} / \mathrm{cm}^{2}\end{array}$ & $\mathrm{FF}$ & $\begin{array}{c}\mu, \\
\%\end{array}$ \\
\cline { 3 - 7 } & $\mathrm{b}-\mathrm{Si}$ & 627 & 34.1 & 0.755 & 16.1 \\
\hline \multirow{2}{*}{ Poly-Si } & Reference & 594 & 30.3 & 0.741 & 13.3 \\
\cline { 2 - 7 } & b-Si & 596 & 32.4 & 0.739 & 14.3 \\
\hline
\end{tabular}

As shown in Table I, the reference solar cells based on the pyramidal surface have the lowest values in the performance parameters. The efficiency of b-Si solar cell samples has been significantly improved. All performance parameters of the b-Si solar cells on monoSi are higher than those of the b-Si solar cells on poly-Si.

Although an especially low surface reflection ratio has been achieved by nanostructured b-Si, the theoretical energy-conversion efficiency of solar cells is not satisfied. The main problems are as follows. The b-Si solar cells suffer from increased surface recombination rates due to the larger surface area resulting in poor spectral response especially at short wavelengths. This effect is often more detrimental for the final device operation than the gain from the reduced reflectance. In addition, chemical contaminations or structural defects introduced by the nanostructure fabrication method are often identified as cause for increased surface defect densities and the related increased surface recombination velocity. Finally, b-Si suffers from aging phenomena; the huge internal surface of the needles tends to be progressively oxidized or contaminated by impurities when in contact with air. The low stability of structural and optical properties over time is crucial for b-Si solar cells.

The only way to overcome these drawbacks is to reduce the introduced surface damage during the fabrication process as well as to effective passivation and stabilization of the needle-like surface. Considering the fact that the gaps among the needles on b-Si are difficult to be covered with conventional passivation film growth method, various solutions need to be tested.

In our work [11] possibility of b-Si passivation with atomic layer deposited (ALD) thin hafnium oxide $\left(\mathrm{HfO}_{2}\right)$ and aluminum oxide $\left(\mathrm{Al}_{2} \mathrm{O}_{3}\right)$ films was analyzed. The general advantage of the ALD method is that it can be used for large area deposition and processed at a low temperature. In addition, this method is easy in its composition control, it has a low cost and it provides uniformity of the film's thickness. With ALD good film quality, accurate thickness control and conformality are reached. The combination of b-Si and $\mathrm{Al}_{2} \mathrm{O}_{3}$ and $\mathrm{HfO}_{2}$ ALD films demonstrates promising results [11].

\section{Conclusions}

The b-Si antireflection layer formation is beneficial compared to conventional wet chemical texturing 
processes. Those results are a very promising alternative for low cost fabrication of Si solar cells, since the process is completely dry, no DI water, wet chemicals and photolithography are used. Still, we feel that with further optimization of b-Si solar cells processing a high efficiency gain is possible. In particular, use of high quality surface passivation could promise an extremely high-efficiency b-Si solar cell.

\section{References}

1. N. Tucher, J. Eisenlohr, P. Kiefel, H. Gebrewold, O. Höhn, H. Hauser, C. Müller, J. C. Goldschmidt, B. Bläsi, Proc. SPIE, 9898, id. 98980F (2016).

2. Soonwoo Kwon, Jongheop Yi. Sewang Yoon, Joon Sung Lee, Donghwan Kim, Current Appl. Phys., 9, 1310-1314 (2009).

3. A.A. Fashina, K.K. Adama, M.G. Zebaze Kana, W.O. Soboyejo, Advanced Materials Research, 1132, 144-159 (2016).

4. S.C. Baker-Finch, C. Simeon, R.M. Keith, Progress in Photovoltaics: Research and Applications, 21, 960-971 (2013).

5. Fu Yun Zhu, Xiao Sheng Zhang, Hai Xia Zhang, Science China - Techn. Sci., 58, 381-389 (2015).

6. Qiulin Tan, Licheng Tang, Haiyang Mao, Yuanjing Chen, Yaohui Ren, Feng Yuan, Wen Ou, Jijun Xiong, Materials Letters, 164, 613-617 (2016).

7. A.B. Roy, A. Dhar, M. Choudhuri, S. Das, S.M. Hossain, A. Kundu, Nanotechnology, 29, 1-12 (2016).

8. M. Otto, M. Algasinger, H. Branz, B. Gesemann, T. Gimpel, K. Füchsel, Advanced Optical Materials, 3, 147-164 (2015).

9. H. Savin, P. Repo, G. Gastrow, P. Ortega, E. Calle, M. Garín, R. Alcubilla, Nature Nanotechnology, 10, 624-628 (2015).

10. G.Y. Ayvazyan, R.N. Barseghyan, Proc. Eng. Academy of Armenia, 12, 355-358 (2015).

11. G.Y. Ayvazyan, R.N. Barseghyan, M.V. Katkov, M.S. Lebedev, Proc. Eng. Academy of Armenia, 14, 474-477 (2017). 